\title{
Algumas observações sobre os empréstimos das línguas bantu no Português de Moçambique
}

\section{Some considerations on Bantu Language Borrowings in Mozambican Portuguese}

BARbARA HLibowiCkA-WĘGLARz [hlibowickaweglarzb@gmail.com] Uniwersytet Marii Curie-Skłodowskiej w Lublinie, Polónia

\begin{abstract}
RESUMO
Moçambique é um país multilingue e multicultural em que a língua portuguesa, língua pós-colonial adotada como língua oficial, encontra-se em situação de contacto com muitas línguas autóctones do ramo bantu que para a maior parte dos Moçambianos constituem a língua materna, sendo utilizadas na comunicação diária. Como resultado da política do Estado, em que o português é também a única língua de ensino, cresceu o número de Moçambicanos que têm português como língua materna. Nas condições acima formou-se uma variedade de português distinta da variedade do português europeu que resulta da diversidade linguística e cultural dos seus usuários. O presente estudo pretende considerar algumas transferências lexicais que ocorrem em contexto sociolinguístico moçambicano, chamadas de moçambicanismos, nomeadamente os empréstimos das línguas bantu que interferem na comunicação, marcando a identidade dos seus falantes.
\end{abstract}

\section{Palavras-Chave}

Português de Moçambique; variedade linguística; moçambicanismo; transferência linguística; empréstimo

\begin{abstract}
Mozambique is a multilingual and multicultural country in which Portuguese, the post-colonial language adopted as the official language, is in contact with many native languages of the Bantu branch that for most Mozambicans constitute the mother tongue and are used in daily communication. As a result of state policy, in which Portuguese is also the only language of instruction, the number of Mozambicans who have Portuguese as their mother tongue has grown. Under the above conditions, a variety of Portuguese has been formed that is distinct from the European variety of Portuguese, which results from the linguistic and cultural diversity of its users. The present study intends to consider some lexical transferences that occur in Mozambican sociolinguistic context, called "mozambicanisms", namely the loans from Bantu languages that interfere in communication, marking the identity of its speakers.
\end{abstract}

\section{KEYWORDS}

Mozambican Portuguese; linguistic variety; mozambicanism; linguistic loan; linguistic transfer

RECEBIDO 2021-04-30; ACEITE 2021-05-17 


\section{Introdução}

Moçambique é um país multilingue e multicultural em que a língua portuguesa (LP), adotada como única língua oficial, se encontra em situação de contacto com muitas línguas autóctones do ramo Bantuํ (LB) que para a maior parte dos moçambicanos são línguas maternas de comunicação diária, assim com algumas línguas asiáticas e o inglês. Esta diversidade linguística resulta, por um lado, de fatores históricos e, por outro, de fatores socioétnicos e geográficos regionais. Como resultado da política do Estado, em que a língua portuguesa é também a única língua de ensino, formou-se uma variedade distinta da variedade do português europeu que resulta "da mistura linguística e cultural de duas civilizações principais: bantu e portuguesa” (Dias 2009: 412).

A interação entre o português, língua usada em contexto formal, com as línguas locais levou ao aparecimento de muitas interferências linguísticas, fenómenos que consistem na utilização na língua portuguesa de muitos traços característicos provenientes das línguas bantu. As referidas transferências ocorrem em diferentes níveis da língua: fonológico, morfossintático e lexical, sendo as últimas muito mais visíveis na língua, devido ao facto de refletirem o ambiente social dos seus falantes.

De modo geral as transferências linguísticas têm como fonte a língua materna. Como a maior parte das transferências provenientes das línguas bantu são lexicais, o presente estudo pretende considerar algumas transferências lexicais das línguas bantu para o português moçambicano, entradas chamadas de moçambicanismos, e dentre eles, os empréstimos das línguas locais.

Para nós os empréstimos lexicais dão-se quando uma dada língua $\mathrm{A}$ integra as unidades lexicais existentes numa outra língua B que a língua A não possuía. Quanto à integração do empréstimo no léxico da língua recetora, Barbosa (1996: 292) constata: "um termo só será considerado empréstimo propriamente dito, quando, numa fase ulterior à da adoção verdadeira pela integração e generalização, tiver alcançado alta frequência e distribuição regular pelos falantes, a ponto de não ser mais sentido como estrangeiro". Por sua vez Timbane (2012: 293) constata que se entende por empréstimo a transformação de uma palavra estrangeira para se adaptar à realidade de uma nova língua. Assim, para o autor mencionado "são palavras que já foram estrangeirismos e que ao longo do tempo se solidificaram na língua e sofreram transformações”.

Na nossa apresentação servimo-nos das entradas citadas no dicionário de autoria de Armando Jorge Lopes, Salvador Júlio Sitoe e Paulino José Nhamuende intitulado: Moçambicanismos. Para um Léxico de Uso do Português Moçambicano, livro publicado em 2002 pela Imprensa Universitária da Universidade Eduardo Mondlane em Maputo ${ }^{2}$. Os autores da referida obra analisam as diferentes formações típicas do PM, entre as quais também as palavras classificadas como emprésti-

1 A palavra bantu é uma forma plural da forma singular muntu. O significado dessa palavra é 'pessoa, gente, ser humano'. O prefixo $b a$ - desempenha nesta palavra as funções iguais às desinências nominais de número das línguas flexivas (p. ex.: o português). O uso da palavra bantu para designar uma grande família de línguas da parte sul do continente africano, provem de um filólogo alemão Bleek que lançou as bases para o estudo científico das línguas dessa grande família africana. Visto que em África existem outras grandes famílias de línguas (afro-aiáticas, khoisan e nilo saarianas), Bleek não podia chamar de "africana" a família que constituia o objetivo do seu estudo e propôs o nome de bantu que foi aceite e até hoje é usado universalmente (Cf. Sá Nogueira 1952: 7).

2 Em Moçambique há apenas dois dicionários impressos dos chamados moçambicanismos. Um deles, intitulado Minidicionário de Moçambicanismos de autoria de Hildizina Dias que foi publicado em 2002, e outro de que nos servimos no nosso estudo. 
mos que se infiltraram das línguas bantu no léxico do português moçambicano. Os investigadores sublinham o facto que entre as entradas citadas há palavras que se distinguem por diferente grau da sua assimilação no PM e explicam que na sociedade moçambicana, plurilingue e multicultural: "uma palavra considerada estrangeira por um falante pode ser considerada doméstica por outro" (LSN:10). Esta observação sugere que existem as diferentes variedades regionais da língua portuguesa em Moçambique que são utilizadas em contextos sociais e regionais muito diversos. Considera-se que a situação de contacto linguístico e o elevado estatuto da língua portuguesa são os fatores de relevo no processo de variação da língua portuguesa em Moçambique (Cf. Menezes 2010). Vale a pena acrescentar que o nosso estudo se baseia nos empréstimos transferidos diretamente das línguas bantu, excluindo outros tipos de formações.

O estudo enquadra-se teoricamente nos trabalhos recentes referentes à situação da língua portuguesa em Moçambique, assim como nos estudos que dizem respeito às transferências lexicais das línguas bantu para o PM. Autores como Firmino (2006), Dias (2009), Gonçalves (1996), Barbosa (1996), Timbane (2012, 2017), Menezes (2010), entre outros, foram de maior importância para o desenvolvimento do presente estudo.

\section{O português moçambicano e as línguas autóctones}

Antes de passarmos à análise dos empréstimos das línguas bantu no PM, é preciso compreender a realidade linguística de Moçambique. Por conseguinte, no que segue, propomos identificar as diversas situações de uso da LP neste país africano, por um lado, reconhecer a importância das línguas maternas, por outro, assim como atribuir as funções sociais às línguas em questão. Desta maneira, pretendemos demonstrar as razões pelas quais o português moçambicano sofreu tantas influências lexicais das línguas autóctones, assim como confirmar a tese de que „toda a variação é condicionada linguisticamente e/ou socialmente, dependendo do contexto linguístico em que se encontram os falantes" (Menezes 2010).

\subsection{O Português Moçambicano}

A presença da língua portuguesa em Moçambique tem a sua longa história ligada aos 500 anos de colonização deste país. Santos (2010: 98; citado por António 2016: 5) descreve a situação da língua portuguesa no período antes da independência com as seguintes palavras:

O registo da institucionalização do Português data do período colonial. A política linguística do governo colonial valorizava os indivíduos que falassem correctamente o Português. Os esforços do governo colonial no ensino do Português aos nativos estavam associados ao facto de as colónias serem províncias ultramarinas e parte integrante do chamado Império Português. O ensino da língua portuguesa era realizado pelas escolas públicas e pelas Missões Católicas. A Concordata de 7 de Maio de 1940 estipulava a obrigatoriedade do ensino em Português em todas as escolas. Para além do Português, podia-se, também usar a língua indígena na catequese. Entretanto em 1921, já fora banido o uso das línguas africanas nas escolas. 
Como se vê, na época colonial o português era imposto aos Moçambicanos pelos colonizadores e falado pela minoria da população. A maior parte da população vivia em meios rurais sem acesso às escolas situadas nos centros da colonização, usando na comunicação diária as línguas do seu grupo étnico. Só no início do século XX, o governo português "começou a preocupar-se em lançar um sistema de educação mais sólido" (Gonçalves 1996), abrindo mais escolas que funcionavam como núcleos importantes para a difusão do português do padrão europeu.

Depois da independência em 1975 a língua portuguesa foi escolhida como língua oficial do país pelo grupo que tomou o poder central. O português tornou-se a única língua de comunicação oficial, a única língua da informação escrita, assim como a única língua do ensino oficial e da alfabetização. Todas as medidas foram tomadas para divulgar a LP no país marcado por inúmeros tipos de problemas, tais como: a falta das escolas, a falta dos professores, ou a falta dos manuais escolares (Cf. Gonçalves 1996: 17).

A adoção do português como uma língua oficial e de ensino teve lugar num contexto em que esta língua pós-colonial coexistia com várias outras línguas, na sua grande maioria nativa. Como diz Santos (2010: 26; citado por António 2016: 8) a decisão de implantação do português no país foi tomada, ignorando todas as questões sociolinguísticas mas priorizando apenas as de natureza ideológica e política:

Em Moçambique, verificamos uma tendência de moçambicanização do português, resultado natural de contacto de línguas. É provável que este facto tenha sido alimentado pelo discurso político de legitimação desta língua desde a independência, em 1975. Nós "nacionalizamos" a LP, mas continuamos com as regras da gramática usada em Portugal. Todavia temos vindo a observar que na expressão quotidiana, jornalistas, apresentadores de programas, políticos e até professores, falam como o cidadão comum, sem rigor que as regras da gramática exigem. Parece também haver um compromisso ou acordo, orientando as pessoas a falarem de um certo modo. Na verdade, o que existe é o espaço comum e uma língua a ser usada de forma diferente. É o português de Moçambique. [...]

As palavras citadas evidenciam que o português falado hoje em dia em Moçambique é uma variedade distinta da europeia e dos outros países da lusofonia, uma variedade misturada, marcada de valores linguísticos e culturais moçambicanos. Nas opiniões de Dias (2009: 410) a língua portuguesa de Moçambique é "uma hibridização cultural e linguística" fortemente influenciada pelas línguas bantu e pela cultura africana. A autora repara que até a escola não consegue funcionar como "guardião e difusora da norma europeia" apesar de muitos esforços da parte de professores, busca de novos métodos, programas e materiais didáticos. Todas as dificuldades mencionadas resultam do facto de os valores linguísticos e culturais em que vivem os alunos diariamente não coincidirem com os valores ensinados na escola. Em consequência, ninguém em Moçambique fala a variedade europeia, "pois é artificial, ou seja, não é língua materna de ninguém” (Timbane 2017: 19). Por sua vez, Bagno (2009: 25) repara que as diferenças entre o português moçambicano e o português europeu são tão marcantes que "se a língua que falamos até hoje se chama português é por mera razão histórica [...]". 
De acordo com Menezes (2010):

O Português de Moçambique tal como afirmam os linguistas moçambicanos, é um português com marcas de interferência linguística das línguas banto para o português padrão falado de acordo com as normas do português europeu. É um português que está em processo contínuo de mudança, quer em razão de não respeito das regras gramaticais do $\mathrm{PE}$, quer em razão da emergência de um novo léxico, derivado de empréstimos lexicais de outras línguas que coabitam com o português falado em Moçambique.

É importante sublinhar que a autora acima citada chama a atenção ao facto de o português em Moçambique estar em processo contínuo de mudança, o que resulta não somente do contacto com as línguas bantu mas também com outras línguas presentes no país, com destaque para a língua inglesa que ganha, cada vez mais, um grande prestígio na comunidade moçambicana. É válido destacar também outras variáveis deste processo de mudança, sobretudo o crescente grau de escolaridade dos Moçambicanos, um fator diretamente ligado a outro, quer dizer, à idade dos falantes. Os dados apresentados em Firmino (2006) põem em evidência que a LP em Moçambique é conhecida, de um modo geral, pela geração mais jovem, entre os 7 anos e os 39 anos, isto é, pelas pessoas que vão à escola.

Embora seja uma língua oficial, única língua de ensino, língua da comunicação pública, assim como língua de unidade social, o português é geralmente falado como língua segunda em Moçambique. A política educacional do país levou ao alargamento da comunidade dos seus falantes e à formação de uma elite escolarizada. O número de falantes de português continua a aumentar sobretudo nas grandes cidades. É interessante reparar que da totalidade das pessoas que falam português em Moçambique quase três quartos (75\%) vivem em meios urbanos que oferecem as melhores condições da vida e o melhor acesso ao trabalho. Como demonstra Chalucuane (2017: 14), entre 1997 e 2007, na cidade de Maputo o número de falantes de português aumentou quase $100 \%$, o que podemos explicar pelo êxodo rural para a capital das outras regiões do país. Maputo como centro financeiro e mercantil oferece os melhores postos de trabalho às pessoas que falam português, os empregos bem remunerados. Por isso, enquanto em 1997, 25\% da população desta cidade falava português, em 2007 este número cresceu para os $43 \%$. Entretanto, essa extensão não se verifica nos meios rurais, nem nas outras províncias do país.

\subsection{As línguas autóctones}

Todas as línguas autóctones faladas em Moçambique são tipologicamente semelhantes e pertencem à família Congo Kordofaniana do ramo Bantu. É necessário reparar que as características morfológicas das LB não correspondem às da LP. Enquanto o português é uma das línguas flexivas, em que todas as informações gramaticais estão cumuladas nos morfemas gramaticais, as línguas bantu pertencem a um grupo de línguas aglutinantes prefixadas, nas quais as categorias gramaticais têm ao seu dispor os diferentes prefixos para a sua marcação. Por isso, a característica 
gramatical mais visível das línguas bantu é o uso extensivo de prefixos ${ }^{3}$. Cada substantivo pertence a uma classe e cada língua pode ter aproximadamente dez classes. A classe é indicada por um prefixo no substantivo, como também em adjetivos e verbos que concordam com aquele. O plural é indicado também por uma mudança de prefixo. Os dados mencionados permitem compreender que até a estrutura gramatical das LB dificulta, ainda mais, o processo da aprendizagem do português neste país africano.

Segundo o site Ethnologue no território do país funcionam quarenta e uma línguas bantu das quais apenas vinte e duas são reconhecidas pelo NELIMO ${ }^{4}$ (Chalucuane, 2017). Por sua vez, Firmino (2002) classifica as línguas locais espalhadas pelo país em oito grupos linguísticos, especificamente: Swahili, Yao, Makhuwa-Lomwe, Nyanja, Nsenga-Sena, Shona, Tswa-Ronga e Cicopi. Cada um dos grupos reúne várias línguas. As línguas com mais falantes no território do país são as seguintes ${ }^{5}$ : Swahili, Macua (Emakhuwa), Tsonga (Xitsonga, Xichangana), Sena (Cisena), Lomwe (Elomwe), Shona (Cishona), Tswa (Xitshwa), Chuabo (Echuwabo), Ronga (Xironga), Marendje, Nyanja (Cinyanja), Chope (Cicopi), Nyungwe (Cinyungwe), Maconde (Shimakonde), Bitonga (Gitonga), Yao (Ciyao). Pode considerar-se que todas as línguas citadas são faladas por quase todos os Moçambicanos. Segundo os dados apresentados em Firmino (2006: 50), 98,8\% da população identifica-se com uma das línguas mencionadas e afirma que conhece uma delas como língua materna. Ao mesmo tempo quase $76 \%$ da população afirma ser falante exclusivo de, pelo menos, uma destas línguas, assim como $23 \%$ da população afirma ser bilingue, falantes de uma língua autóctone e do Português (Hlibowicka-Węglarz 2010: 81).

Vale a pena sublinhar que as línguas locais moçambicanas se encontram marginalizadas ${ }^{6}$ em situações oficiais. São usadas sobretudo na comunicação entre pessoas do mesmo grupo étnico, entre membros da família, na vida quotidiana, assim como em algumas interações sociais como: campanhas de alfabetização de mulheres ou crianças ou atividades religiosas. Deste modo, marcam sobretudo as relações de etnicidade, identificando a região do país de onde provêm. No entanto, as línguas locais não desapareceram da zona central do país, região mais industrializada e mais desenvolvida cujos habitantes têm um grau de escolaridade muito mais alto em relação aos meios rurais e mantêm-se faladas "em ambientes de trabalho, sobretudo entre funcionários não superiores e operários” (Firmino 2006: 83).

3 Sobre a estrutura morfológica das línguas bantu, ver: Dicionário de termos linguísticos, vol II, Brown (2011), https:// pt.wikipedia.org/wiki/L\%C3\%ADngua_aglutinante .

4 O Centro de Estudos de Línguas Moçambicanas criado em 1980 pelo Prof. Doutor Eugeniusz Rzewuski.

5 De acordo com Firmino (2006).

6 A referida marginalização das línguas bantu tem a sua longa história que data dos tempos coloniais quando as línguas autóctones, tanto de Moçambique, como de Angola eram menosprezadas e, por consequência, chamadas de língua do cão, língua dos pretos ou de pretoportuguês. Como diz Timbane (2017: 22): "Essa atitude preconceituosa valorizou a LP e cada vez mais se consolidava o mito que defendia que "quem falasse português era civilizado ou assimilado". 


\section{Os empréstimos das línguas bantu no Português de Moçambique}

No processo de aquisição de uma segunda língua há sempre interferências de línguas maternas devido ao facto de que "a língua materna predomina na mente do falante e tende a interferir nas línguas aprendidas em segundo lugar” (Menezes 2010). Por isso, não estranha que as línguas bantu, línguas maternas da maior parte dos moçambicanos, enriqueceram fortemente a variedade do português falado neste país.

Os empréstimos presentes em PM diferenciam entre si quanto à sua origem, às suas formas (processos da sua formação), assim como ao seu sentido, isto é, à referência a diferentes aspetos da vida quotidiana dos seus usuários. Como argumentam os autores do dicionário que nos serve de base, os empréstimos caracterizam-se também pela variação de estilos diferentes, como p.ex.: estilo formal vs. informal que podemos observar tanto na fala como na escrita, estilo coloquial observável sobretudo na fala, e neutro, em qualquer estilo. Os autores falam também da variação de registos distintos, como p ex.: linguagem própria ou especializada de um grupo particular dos indivíduos, isto é, gíria ou calão, geralmente com sentido depreciativo ou pejorativo (LSN: 12).

\subsection{Origem dos empréstimos das línguas bantu no PM}

Uma longa convivência do português com as línguas bantu deu em resultado muitos empréstimos vindos de todas as línguas autóctones faladas no país. Tendo em conta o número de falantes de cada uma das línguas, o papel que assume na comunidade linguística, assim como o estatuto social dos seus falantes, verifica-se que umas línguas infiltraram mais empréstimos em relação às outras. Neste contexto, as línguas mais representativas do país e sobretudo faladas nas zonas urbanas implantaram-se mais profundamente no léxico, introduzindo no PM um grande número das unidades lexicais do seu grupo étnico. De modo geral, os empréstimos em questão estão inteiramente assimilados no PM. É preciso acrescentar ainda que as interferências das línguas bantu no PM são mais percetíveis a nível oral. Antes de passarmos à nossa análise, vale a pena notar que todos os empréstimos que citamos no presente estudo são exemplos das transferências diretas das línguas bantu.

Comecemos pelos empréstimos da língua Macua (Emakhuwa) que é a língua com o maior número de falantes no país, falada por mais de 3200 mil Moçambicanos ${ }^{7}$, isto é, por 26,3\% da população, sobretudo nas províncias de Nampula, Cabo Delgado e Niassa no norte do país, assim como em Maputo-Cidade situado no sul (LSN: 62). Os falantes do Macua vivem na sua maioria no litoral próximo da Ilha de Moçambique. A principal atividade económica do povo é pescar e o comércio de peixe. O Macua é também uma língua falada na República Unida da Tanzânia. Eis alguns exemplos dos empréstimos provenientes desta língua bantu, entradas que são muito frequentes:

7 Tendo em conta que os dados demográficos estão em constante mudança, notamos que os dados referentes ao número de falantes das línguas em análise provêm do dicionário Moçambicanismos (2002). No entanto, vale a pena acrescentar que de acordo com estimativas das Nações Unidas, em 2100 Angola e Moçambique terão, em conjunto, mais de 260 milhões de habitantes, ultrapassando largamente o Brasil, que a parir de 2050, verá a sua população começar a diminuir. O português tornar-se-á uma das línguas dominantes no continente africano, a par do inglês e do árabe (Novo Atlas da Língua Portuguesa 2016: 56). 
- mucunha, n. - indivíduo de cor branca, por extensão: patrão

- mujekele, n. - tipo de bebida alcoólica de fabrico caseiro, à base de caju

- nikawane, n. - polícia

- nthipfe, n. - festa relacionada com os ritos de iniciação femininos entre os Makuas

- quizumba, n. - hiena, associação a algo negativo, a inimigo

- wasuwasu, n. - feitiço para provocar num indivíduo coisas boas ou más (paixões, malefícios, etc.).

A língua Tsonga (Xitsonga, Xichangana) é a segunda língua bantu com mais falantes no país. É falada por 1400 mil moçambicanos, isto é, por 11,4\% da população, nas províncias do sul do país: Gaza, Maputo e Maputo-Cidade (LSN 2002: 149). Como se vê, são as palavras usadas com muita frequência na variedade falada na capital e nas províncias vizinhas:

- kokuana, n. - avô, pessoa idosa

- pfhukar, v. - ato do morto se vingar contra a pessoa ou família da pessoa que em vida lhe fez algum mal

- mangungo, n. - o almoço que o trabalhador leva de casa para o serviço que come no intervalo do trabalho

- njingiritana, n. - criança muito pequena, recém-nascida

- zanguangua, n. - indivíduo engarrafado e sob o efeito do feitiço a que mulher recorreu

A língua Sena (Cisena) é uma língua bantu falada por mais de 870 mil moçambicanos (7\% da população) nas províncias: Sofala, Manica, Zambézia e Tete, isto é, províncias centrais do país (LSN: 51). Entre os empréstimos do Sena podemos citar os seguintes exemplos:

- sundzar, v. - procurar algo para o sustento

- nyamussoro, n. - espiritista que estabelece a comunicação entre os vivos e os mortos

- muzungo, n. - senhor, pessoa de cor branca

A língua Ronga (Xironga) é falada por mais de 480 mil moçambicanos (3,9\% da população) na capital e arredores dela onde há a maior concentração das pessoas no país (LSN: 153). Eis alguns exemplos dos empréstimos da língua Ronga:

- dumba-nengue, n. - comércio informal no sul do país

- kanimambo, n. - obrigado, estar agradecido

- nholar, v. - ato de iniciar um jogo ou passatempo que requer a intervenção de vários participantes

- timhamba, n. - designa as preces e as cerimónias feitas em honra de familiares defuntos

A língua Chope (Cicopi) é falada por mais de 310 mil moçambicanos, isto é, por 2,5\% da população, nas províncias de Inhambane, Gaza e Maputo-Cidade (LSN: 50). O mapa da distribuição das línguas em Moçambique permite reparar que nas províncias mencionadas o Chope pode concorre com a língua Macua. Eis alguns exemplos provenientes dela: 
- feijão-nhemba, n. - tipo de feijão que mais se produz e consome na maior parte de Moçambique

- kanganhiça, n. - aldrabice, pequena mentira

- milando, n. - problema, imbróglio

- mshao, n. - sarau cultural relacionado com música, canto, dança e poesia

- xiluva, n. - rapariga ou mulher bonita

O dicionário abrange também muitos empréstimos provenientes das outras línguas bantu, menos faladas, como por exemplo:

- mugonzice, n. - do Tswa (Xitshwa) - educador

- tamwene, n. - do Lomwe (Elomwe) - ato consentido de troca de esposas entre casais

- nkoteko, n. - do Nyungwe (Cinyungwe) - calcinha

- zungar, v. - do Nyungwe (Cinyungwe) - ato de alguém procurar algo para o seu sustento

- suruma, n. - do Maconde (Shimakonde) - droga, marijuana

- culimar, v. - do Chuabo (Echuwabo) - cultivar, capinar

Os exemplos acima citados exigem um comentário. É preciso compreender que as línguas autóctones de Moçambique, línguas bantu, são distribuídas regionalmente. Geralmente cada língua local falada por um moçambicano identifica o seu grupo étnico a que ele pertence e também a zona de que ele provém. Sendo assim, a língua materna dos falantes da província de Nampula é a língua Macua, e da província de Maputo é a Xichangana. Na Cidade de Maputo, tanto o Ronga como o Tsonga são predominantes, com uma percentagem quase igual de falantes nativos (Firmino 2006: 63). O autor referido afirma que, quando um moçambicano fala mais de uma língua, situação cada vez mais frequente no país, este facto quer dizer que ele emigrou de uma zona para a outra, ou está em contacto profissional com pessoas de língua diferente do seu grupo étnico. Os dados apresentados podem sugerir que na maior parte de casos os empréstimos provenientes de uma dada língua serão usados em certas províncias pela população dum determinado grupo étnico. Hoje em dia, com as migrações da população para os centros urbanos a situação tornou-se muito mais complexa.

\subsection{Referência à tradição e à cultura}

Os exemplos apresentados evidenciam que os empréstimos das línguas bantu na sua maioria se referem à tradição e à cultura da população e servem para designar a realidade em que vivem e trabalham os moçambicanos. Como repara Abdula (2017) por via de empréstimos o português de Moçambique vai ganhando novas feições e vai criar uma identidade própria, carregando marcas de identidade dos seus falantes. Para provar o que foi dito, vamos agrupar todos os empréstimos em análise em áreas semânticas, de acordo com o seu significado. Todas as entradas abaixo referem-se ao mundo da realidade moçambicana. 
Os pratos tradicionais:

- chima, n. - massa feita a partir de farinha de milho, mapira, mexoeira, mandioca

- mutlhutlhu, n. - tipo de petisco para acompanhar a bebida, feita partir de vísceras de vaca ou cabrito, partes de cabeça de vaca ou ainda moelas ou patas de galinha

- tricofaite, n. - bebida que consiste na mistura de vinho (em geral vinho verde) com ginger-ale

- penalte, $\mathrm{n}$. - bebida que consiste na mistura de whisky com ginger-ale

- xibida-ndota, n. - bebida com elevado teor de álcool feita à base de toranja

A designação dos membros da família ou diferentes tipos humanos:

- kokuana, n. - avô, pessoa idosa

- madala, n. - homem idoso

- mamana, n. - mãe, mulher adulta casada ou viúva

- mufana, n. - garoto, miúdo

- mulungo, n. - pessoa de cor branca, também patrão (de qualquer cor)

- tombazana, n. - jovem de sexo feminino

Diferentes profissões:

- gueva, n. - compradora-revendedora de mercadorias, no contexto do mercado informal

- nikawane, n. - polícia

- walumua, n. - polícia camarária da cidade da Beira, assim designada pela população pelo facto de fazerem constantes rusgas contra os vendedores de rua

- nyanga-muloi, n. - médico tradicional-feiticeiro

As crenças, as cerimónias e os rituais tradicionais:

- mpfhukwa, n. - espírito, a crença diz que um mandau, depois de morto, se torna não só num espírito, mas também um espírito vivo, um ser ressuscitado que se vai vingar daqueles que lhe fizeram mal em vida

- kuloia, n. - causar malefícios a alguém por meio do tratamento ou "feitiço" artificial ou do "feitiço" natural do muloy

- mbelele, n. - cerimónia ritual que se realiza para esconjurar males ou calamidades naturais como, por exemplo, secas prolongadas e pestes ou pragas que afetam as culturas

- timhamba, n. - cerimónias feitas em honra de familiares defuntos

- lobolo, n. - casamento tradicional na região sul do país

- tamwene, n. - ato de troca de esposas entre os casais

- folhar, n. - ato da rapariga sair de casa dos pais para se juntar ao namorado

Os espiritistas:

- muloyi, n. - feiticeiro causador de malefícios a terceiros

- nyamussoro, n. - espiritista que estabelece a comunicação entre os vivos e os mortos 


\section{A flora e a fauna:}

- massala, n. - fruto de casca dura e de forma esférica, primeiro de cor verde, e amarelo depois de maduro

- feijão-nhemba, feijão cafreal, n. - tipo de feijão que mais se produz e consome na maior parte de Moçambique

- feijão macaco, n. - planta trepadeira com uma penugem que ao toque provoca comichão

- xidambela, n. - inseto comestível que as crianças caçam e assam

Objetos de uso quotidiano:

- kavelávela, n. - tipo de faca, de forma curva, geralmente usada na região norte de Moçambique para cortar paus, capim, etc.

- capulana, n. - peça do vestuário de forma retangular, de algodão, que as mulheres, em geral, ajustam à cintura ou sobre o peito

- matambira, n. - dinheiro

- xiphefo, n. - candeeiro lamparina a petróleo feito a partir de uma garrafa ou lata, na qual se faz um furo para o pavio ou torcida.

- calamidade, n. - roupa usada a baixo preço

Além dos empréstimos acima citados o dicionário reúne muitos outros que se referem às atividades quotidianas, tais como: gonar (dormir), culimar (cultivar a terra), mapandzar (divertir-se), gungular (encontrar), babalazar (falar muito), dudar (fazer bastante dinheiro), chuapar (roubar), etc. Vale a pena citar também algumas interjeições de origem bantu, frequentemente usadas no PM, tais como: Bayete (Viva! Salve!), nyandayeyo (socorro!), suca (Sai! Vai-te embora!), etc.

Todas as palavras mencionadas são usadas na língua quotidiana e servem para marcar a identidade étnica do falante, por um lado, como p. ex.: khanimambo (obrigado), ou são usadas pela necessidade de referência a uma realidade tradicional moçambicana que não encontra o equivalente na variedade do português europeu, única norma aceite no território do país, por outro, como p. ex.: xiguinha (prato característico no sul de Moçambique). Todas elas são unidades lexicais que ocorrem em contexto sociolinguístico moçambicano que particularizam a variação lexical (Timbane 2017: 35).

\subsection{Processos de formação}

Quanto à forma dos empréstimos das línguas bantu destacam-se as palavras formadas pela composição em geral, assim como pela reduplicação.

Os empréstimos formados pela composição são frequentes. Vejam-se a este propósito, os substantivos, como:

- dumba-nengue, n. - comércio informal

- feijão-nhemba, n. - tipo de feijão 
- mucunha-oripa, n. - patrão de cor negra

- bebe-tchukumeta, n. - garrafa vasilhame em geral de cerveja

- tchowa-xitaduma, n. - tipo de carrinho puxado à mão, geralmente de duas rodas

- chupa-sangue, n. - uma crença em seres misteriosos que são supostos extrair o sangue das pessoas que dormem

- curandeiro-feiticeiro, nyanga-muloyi, n. - médico tradicional-feiticeiro

- padre-muanacaja,n. - freira, etc.

É interessante reparar que a palavra bebe-tchucumeta representa uma formação mista em que um elemento é de origem do português e o outro provém das línguas bantu. O mesmo pode-se dizer sobre o empréstimo padre-muanacaja constituído por um elemento da língua portuguesa (padre) e outro de uma língua bantu (muanacaja).

A reduplicação é uma das variantes da formação das palavras pela composição em que as duas formas são idênticas ou apenas ligeiramente diferentes, o que podemos observar nos seguintes empréstimos:

- waya-waya, n. - indivíduo sem personalidade

- hoyo-hoyo, interj. - bem-vindo, dar as boas-vindas

- ngutu-ngutu ${ }^{8}$, adv. - principalmente, sobretudo, também: bastante

As entradas citadas provam que a reduplicação, como um processo morfológico de criação das palavras novas, é geralmente usada para indicar uma função gramatical, reforçar a intensidade (p. ex.: hoyo-hoyo, nguu-ngutu) ou pluralidade (p. ex.: waya-waya). É usada também com muita frequência com objetivos expressivos, isto é, quando um falante se serve de um tom mais afetivo ou figurativo do que numa conversação normal. Repare-se que a reduplicação está presente em diversas línguas e grupos linguísticos, incluindo as línguas mistas, tais como línguas pidginizadas e línguas crioulas. É uma estratégia muito frequente. Em português podemos dizer também: este livro é muito, muito bom para acrescentar a ideia de que gostamos mesmo do livro. No entanto, neste exemplo a repetição da palavra muito não pode ser considerada como processo morfológico de formação de uma palavra nova.

É interessante observar ainda que entre os empréstimos por nós analisados se encontram também as formações que representam a composição por aglutinação em que se reduplicam não todas as palavras mas apenas as sílabas, como p. ex.: wasuwasu (mãe) ou mamana (feitiço).

\subsection{Variação de registos distintos}

A noção de registo caracteriza as variações da prática linguística dos falantes que podem depender da natureza das relações entre eles, das suas intenções, dos temas abordados, do grau de formalidades ou de familiaridade (Cf. DDL: 615). Assim, o uso das palavras numa língua depende da diversidade das situações de comunicação em que se encontra o falante.

8 O advérbio provém da língua Cicopi. Na língua Xichangana tem a forma de ngopfu-ngopfu, na lingua Emakhuwa vinci-vinci. Em todas línguas tem o mesmo significado. 
Na descrição de todas as entradas que se encontram no dicionário, os autores incluem também uma informação sobre os registos da língua a que pertence cada uma das entradas. Enquanto os empréstimos considerados de estilo neutro designam as palavras utilizadas pela maioria dos membros da comunidade moçambicana, os chamados coloquialismos são as entradas usadas em situações que não exigem formalidades, sobretudo em família ou entre amigos. Os autores citam também algumas entradas que classificam de calão, quer dizer, do nível da língua de carácter expressivo, humorístico, transgressor ou ofensivo, usado em situações informais de comunicação (DLP: 280), assim como de gíria que, por sua vez, determina um grupo de pessoas que se caracteriza por mesma profissão ou por mesmos interesses (LSN: 12). Tendo em conta a variação do registo que representam, podemos classificar os empréstimos em vários grupos.

Formas consideradas neutras de estilo nacional:

- banja, n. - reunião onde se resolvem assuntos relevantes de uma comunidade

- cacimba, cacimbo, n. - neblina, nevoeiro

- candonga, n. - venda de produtos com preços acima dos fixados oficialmente

- catembe, n. - região situada na margem sul da baía de Maputo; bebida apreciada que consiste na mistura do vinho (em geral, tinto) com coca-cola

- dumba-nengue, n. - comércio informal no sul do país

- iduna, n. - termo muito empregue no período colonial para designar um auxiliar do régulo ou chefe tradicional

- machamba, n. - campo agrícola, terra de cultivo

Formas consideradas neutras de estilo regional:

- magandzelo, n. - altar sagrado, geralmente representado por uma árvore sagrada

- nthipwe, n. - festa relacionada com os ritos de iniciação femininos entre os macuas

- pfhukar, v. - ato de um morto se vingar contra a pessoa ou família da pessoa que em vida lhe fez algum mal

- timhamba, n. - as preces e as cerimónias feitas em honra de familiares defuntos

Coloquialismos moçambicanos (de uso nacional):

- babalazar, v. - falar muito

- babar, v. - usar de artimanhas para obter certos favores ou conseguir algo de alguém

- fembar, v. - ação do espiritista para agarrar o espírito ou espíritos maléficos que atormentam as pessoas e para as esconjurar de forma a que pessoas, negócios, etc. fiquem livres desses espíritos

- mamana, n. - mãe ou mulher adulta. O termo é também usado para designar carinhosamente tanto a senhora doméstica como a vendedeira do mercado.

- nhoca, n. - cobra

- renamista, n. - alguém que é membro ou simpatizante do Partido Renamo

- sura, n. - suco extraído de várias palmeiras, em especial do coqueiro

- xicorocoro, n. - carro velho 
Coloquialismos regionais:

- chuapar, v. - roubar

- kanganhiça, n. - aldrabice, pequena mentira

- gwadjiçar, v. - interpelação do citadino pelo ladrão

- madiba, n. - designação clânica da chefatura dos Thembu. Hoje em dia é também uma designação informal e afetiva para referir Nelson Mandela. O termo madiba designa também o tipo de camisas usadas por Mandela

- mafuta, n. - forma de tratamento familiar equivalente a ó gordo.

- ximakwa, n. - indivíduo de estatura muito baixa

Exemplos de gíria:

- farawa, n. - suruma menos forte, droga de baixa qualidade

- tchunar, v. - vestir à moda, estar bem vestido (gíria juvenil)

- xifaki, n. - suruma, droga

Empréstimos considerados de calão:

- famba!, interj. - vai-te embora! Insultuoso (uso nacional)

- muanambua, n. - filho de cão, filho da mãe (termo pejorativo de uso nacional)

- waya-waya, n. - indivíduo sem personalidade, pouco sério, também gajo (termo pejorativo de uso regional)

Os exemplos acima põem em evidência que para transmitir a mesma informação o falante pode recorrer a vários registos em função das circunstâncias em que se encontra. Tendo em conta o facto de os moçambicanos na sua grande maioria não falarem português como língua materna, usam no seu dia-a-dia muitos coloquialismos vindos das suas línguas autóctones, tanto de uso nacional como regional. Todas estas formas contribuem para alimentar a sua língua comum, particularmente as suas variedades orais e familiares.

\section{Conclusão}

A língua tem uma função de comunicação e só pode ser compreendida nos contextos socioculturais em que se insere. Neste contexto, o português falado em Moçambique não constitui um sistema homogéneo, mas pode ser considerado como um conjunto de variedades moldadas por diferentes condições sociais e culturais existentes no país.

Devido às variáveis sociais e culturais que marcam a população moçambicana, entre as quais o nível de escolaridade, o lugar de residência, ou a língua de origem, o português falado em Moçambique distancia-se do português europeu, carregando, em maior ou menor grau, os traços característicos provenientes das suas línguas maternas. 
O elevado número dos empréstimos vindos das diferentes línguas bantu no português moçambicano justifica-se pelo contacto entre o português, língua oficial do país, e as numerosas línguas maternas da população moçambicana usadas na comunicação diária. Os Moçambicanos usam os empréstimos das suas línguas autóctones para manifestar a sua origem étnica, ou por necessidade, quando não encontram em português europeu a palavra equivalente. No segundo caso, recorrem ao empréstimo para preencher lacunas no conhecimento do português, o que resulta do fraco domínio da LP, língua não-materna deles. Este tipo de recurso caracteriza qualquer aprendente de uma segunda língua. Neste contexto, o nível de escolaridade influencia na redução de uso dos empréstimos que ocorrem com maior frequência em falantes de nível baixo, o que implica também um baixo grau de escolaridade.

Os empréstimos remetem para classes de entidades e de conceitos muito diversos. A sua classificação pode ser organizada de acordo com diferentes critérios, entre os quais: a língua de origem, a sua forma, o conteúdo semântico, assim como a variedade de língua definida de acordo com o seu uso em diferentes situações sociais.

\section{Referências bibliográficas}

Abdula, R. A. M. (2017). A criatividade da língua portuguesa: estudo de moçambicanismos no português de Moçambique. Revista Internacional de Língua Portuguesa, 32, 81-97. <https://www.rilp-aulp.org/index. php/rilp/article/view/RILP2017>

António, D. (2016). A língua portuguesa em Moçambique e as práticas de subjetivação: acontecimento, materialidade e memória. Anuais de V Congresso Internacional de História. Jataí -Go. <http://www.congresso2016.congressohistoriajatai.org/conteudo/view>

Bagno, M. (2009). Não é errado falar assim! Em defesa do português brasileiro. São Paolo: Editorial Parábola. Barbosa, M. A. (1996). Léxico, produção e criatividade. Paris: Pléiade.

Chalucuane, B. D. P. (2017). A inluência das línguas bantu no português em Moçambique: um estudo descritivo do Cindau. Editora da Universidade Federal de São Carlos. <https://repositorio.ufscar.br/browse?type $=$ author\&value $=$ Chalucuane $\% 2 \mathrm{C}+$ Beatriz + Damaciano + Paulo $>$

Dias, H. N. (Org.) et al. (2009). Português Moçambicano. Estudos e reflexões. Universidade Eduardo Mondlane.

Dicionário da Língua Portuguesa. (2010). Porto: Porto Editora.

Firmino, G. (2006). A Questão Linguística na África Pós-Colonial. O caso do Português e das Línguas Autóctones em Moçambique. Maputo: Texto Editores.

Galisson, R.; Coste, D. (1983). Dicionário de didáctica das línguas. Coimbra: Livraria Almedina.

Gonçalves, P. (1996). Português em Moçambique: Uma variedade em formação. Faculdade de Letras, Livraria Universitária.

Hlibowicka-Węglarz, B. (2010). Para compreender a situação linguística em Moçambique. Studia Iberystyczne, 9, 77-87.

Lopes, A. J.; Sitoe, S. J.; \& Nhamuende, P., J. (2002). Moçambicanismos. Para um Léxico de Usos do Português Moçambicano. Livraria Universitária, Universidade Eduado Mondlane. 
Menezes, L. (2010). Descosturando a língua: o caso da mudança e das interferências no Português de Moçambique“, Odisseia, 5. < https://periodicos.ufrn.br/odisseia/article/view/2028/1463>

Sá Nogueira, R. (1952). As Línguas bantas e o português. Lisboa: Instituto de Línguas Africanas e Orientais.

Reto, L. A.; Machado, F. L.; \& Esperança, J. P. (2016). Novo Atlas da Língua Portuguesa. Lisboa: Imprensa Nacional - Casa da Moeda.

Timbane, A. A. (2012). Os estrangeirismos e os empréstimos no português falado em Moçambique. Cadernos de Estudos Linguísticos, 54, 2, 289-306.

Timbane, A. A. (2017). A variação linguística do português moçambicano: uma análise sociolinguística da variedade em uso. Revista Internacional de Língua Portuguesa, 32, 19-38.

\section{Abreviações usadas no estudo}

[DDL]: Galisson, R., Coste, D. (1983). Dicionário de didáctica das línguas. Coimbra: Livraria Almedina. [DLP]: Dicionário da Língua Portuguesa. (2010). Porto: Porto Editora.

[LSN]: Lopes, A. J.; Sitoe, S. J.; \& Nhamuende, P. J. (2002). Moçambicanismos. Para um Léxico de Usos do Português Moçambicano. Livraria Universitária, Universidade Eduado Mondlane.

adv.: advérbio

interj.: interjeição

n.: nome

v.: verbo 